\title{
Brain-Derived Neurotrophic Factor and Neurotrophin-4/5 Stimulate Growth of Axonal Branches from Regenerating Retinal Ganglion Cells
}

\author{
Hajime Sawai, David B. Clarke, Paula Kittlerova, Garth M. Bray, and Albert J. Aguayo \\ Centre for Research in Neuroscience, Montréal General Hospital Research Institute and McGill University, Montréal, \\ Québec, Canada H3G 1A4
}

To investigate the influences of growth factors on axonal regeneration in the mammalian CNS, we used intracellular tracers to quantitate the effects of brain-derived neurotrophic factor (BDNF), neurotrophin (NT)-4/5, or NT-3 on individual retinal ganglion cell (RGC) axons in the retinas of adult rats after optic nerve transection. A single injection of BDNF or the prolonged administration of NT-4/5 by mini-pump increased axon branch median lengths by eightfold but had no effect on the number of branches formed by the RGC axons. NT-3 did not significantly influence axonal regrowth. These specific in vivo effects of BDNF and NT-4/5 on axonal regeneration from injured RGCs may be used to promote growth and expand the abnormally small terminal arbors observed when RGCs regrow into their CNS targets.

Key words: axon branching; BDNF; NT-4/5; neurotrophins; axon regeneration; retina
Recovery from neural injury is often impaired by a loss of nerve cells and the failure of regenerating axons to grow and branch appropriately in the adult mammalian CNS. We have shown previously in adult rats that the intraocular injection of brainderived neurotrophic factor (BDNF) enhances the survival of axotomized retinal ganglion cells (RGCs) (Mansour Robaey et al., 1994). The BDNF injections also caused the formation of a dense and intricate meshwork of axons within the retinas of these animals (Mansour-Robaey et al., 1994). Such an observation suggested that BDNF could promote the regrowth of injured RGC axons in adult mammals. On the other hand, Schnell et al. (1994) reported that neurotrophin (NT)-3, but not BDNF, enhanced axonal sprouting in the injured spinal cord of rats. Such apparent discrepancics may have reflected differences in NT receptor expression in separate classes of CNS neurons. In both of these experiments, however, the precise actions of the NTs on axonal regeneration were difficult to define because increases in fiber density at the site of injury could have resulted from a greater number of axons, an increase in their branching, or a larger population of surviving nerve cells.

In the present investigations, we have exploited the accessibility of the retina and used intracellular tracers to visualize fine details of the course and termination of individual regenerating axons and their branches. Measurements in untreated and NT-treated retinas have then been used to delineate specific in vivo effects of the NTs-BDNF, NT-3, and NT-4/5 - on intraretinal growth and branch formation by $\mathrm{RGC}$ axons. We anticipate that a better understanding of the nature of the axonal changes induced by

\footnotetext{
Received Jan. 1, 1996; revised March 18, 1996; accepted March 26, 1996.

This work was supported by the Canadian Neuroscience Notwork, the Medical Research Council of Canada, and the Multiple Sclerosis Society of Canada. We thank Jane Trecarten, Margaret David. Janet Laganière, and Wendy Wilcox for technical assistance.

Correspondence should be addressed to Albert J. Aguayo, Centre for Research in Neuroscience, 1650 Cedar Avenue, Montréal, Québec, Canada H3G 1A4.

Dr. Sawai's present address: Department of Welfare and Health Science, Okayama Prefectural University, 111 Kuboki, Souja, Okayama 719-11, Japan. Copyright $\odot 1996$ Society for Neuroscicnce $0270-6474 / 96 / 163887-08 \$ 05.00 / 0$
}

individual NTs in the adult mammalian CNS will provide new insights on the molecular determinants of axonal phenotypes. Such knowledge may also help develop in vivo strategies to enlarge the arborizations of regrowing axons, which are smaller than normal when RGCs regenerate into the superior colliculus (SC) along peripheral nerve grafts that connect the eye and the tectum (Carter, 1991; Carter et al., 1991; Sauvé et al., 1995).

\section{MATERIALS AND METHODS}

Animals. In 67 adult female Sprague-Dawley rats, the left optic nerve (ON) was transected $0.5 \mathrm{~mm}$ from the eye. At the time of $\mathrm{ON}$ transection, RGCs were back-labeled by the application of 4Di-10Asp (Di-Asp, Molecular Probes, Eugene, OR) to the ocular stump of the ON. In four animals without previous ON lesions, the left $O N$ was transected only at the time of removal of the retina for in vitro $\mathrm{RGC}$ labeling.

NT administration. Five micrograms of BDNF or NT-3, or $3 \mu \mathrm{g}$ of NT-4/5 (provided by Regeneron Pharmaceuticals) in $5 \mu$ l of PBS, pH 7.2, was injected into the vitreous space by a posterior injection at the time of ON transection. Care was taken to avoid injury to anterior structures of the cye, known to be a potential source of trophic molecules capable of influencing RGC responses to axotomy (Mansour-Robacy et al., 1994). For sustained administration, an osmotic mini-pump (Alzet \#2002) filled with NT-4/5 $(0.1 \mu \mathrm{g} / \mu \mathrm{l})$ was placed in a subcutancous pocket. The NT was delivered to the vitreous chamber through a fine SILASTIC tubing (Dow Corning, Corning, NY). The mini-pump contained $0.1 \mu \mathrm{g} / \mu \mathrm{l} \mathrm{N}^{\mathrm{T}}-4 / 5$ that was delivered at approximate rates of $0.5 \mu \mathrm{l} / \mathrm{hr}$ for $14 \mathrm{~d}$.

Tissue processing. Groups of rats were perfused with aerated Ames' solution immediately after $\mathrm{ON}$ transection or $3 \mathrm{~d}$ or 1,2 , or 4 weeks later. The retinas were quickly dissected, flat-mounted, and superfused with aerated Ames' solution in a Plexiglas chamber on a fixed-stage epifluorescence microscope.

Visualization of individual RGCs. RGC perikarya were identified by fluorescence microscopy on the basis of their labcling with Di $\Lambda$ sp. Individual neurons were then injected by iontophoresis through micropipettes (0.1-0.5 $\mu \mathrm{m}$ tips) with $4 \%$ Neurobiotin (Kita and Armstrong, 1991). Nine to fifteen RGCs were injected per retind over 4-6 hr. Perfusion with the aerated Ames' solution continued for an additional 30 min after the last injection. The retinas were then fixed overnight by immersion in $4 \%$ paraformaldehyde and $0.25 \%$ glutaraldehyde in phosphate buffer. Each retina was incubated at $4^{\circ} \mathrm{C}$ for $2 \mathrm{~d}$ with the detergents $2 \%$ Triton X-100 and $0.5 \%$ DMSO in PBS. Experimental and control retinas were immersed overnight at room temperature in a solution of streptavidin-conjugated peroxidase in $2 \%$ Triton X-100 and $0.5 \%$ DMSO. 


\begin{tabular}{|c|c|c|c|c|c|}
\hline & $4-6 \mathrm{hr}$ & $3 \mathrm{~d}$ & 1 week & 2 weeks & 4 weeks \\
\hline Retinas $(n)$ & 4 & 4 & 3 & 11 & 4 \\
\hline Labeled axons $(n)$ & 52 & 47 & 25 & 92 & 27 \\
\hline Retracted $^{a}$ & $20(38 \%)$ & $16(34 \%)$ & $11(44 \%)$ & $37(40 \%)^{c}$ & $12(44 \%)$ \\
\hline With growth cones ${ }^{b}$ & $85 \%$ & $63 \%$ & $55 \%$ & $95 \%$ & $58 \%$ \\
\hline Axons with branches & $16(31 \%)$ & $10(21 \%)$ & $7(28 \%)$ & $38(41 \%)$ & $6(22 \%)$ \\
\hline Branches/axon & 16.8 & 11.6 & 8.4 & 6.8 & 20.8 \\
\hline Range & $3-13$ & $1-45$ & $8-23$ & $1-42$ & $2-67$ \\
\hline \multicolumn{6}{|l|}{ Branch length } \\
\hline Median $(\mu \mathrm{m})$ & 2.7 & 7.5 & 6.5 & 9.0 & 5.7 \\
\hline Range $(\mu \mathrm{m})$ & $0.7-14.4$ & $2.0-125.4$ & $2.7-26.4$ & $1.7-1860.4$ & $1.8-203.5$ \\
\hline$<5 \mu \mathrm{m}$ & $87 \%$ & $56 \%$ & $53 \%$ & $26 \%$ & $37 \%$ \\
\hline$>50 \mu \mathrm{m}$ & $0 \%$ & $4 \%$ & $2 \%$ & $21 \%$ & $3 \%$ \\
\hline
\end{tabular}

${ }^{a}$ Axons that end outside the ON head or at its edge.

${ }^{b}$ Proportion of axons outside the $\mathrm{ON}$ head that had growth cones.

${ }^{c}$ The ending of two axons could not be identified.

After rinses, the retinas were incubated in phosphate buffer $(0.1 \mathrm{M})$ containing diaminobenzidine $(50 \mathrm{mg} / 100 \mathrm{ml})$, cobalt chloride $(0.002 \%)$, and $\mathrm{H}_{2} \mathrm{O}_{2}(0.01 \%)$. The retinas were flat-mounted in Permount and examined by light microscopy.

$\mathrm{RGC}$ axons were categorized according to the pattern of their termination as well as the number and lengths of their branches. Because of overlapping of axons and branches, 21 of the 470 labeled axons in the 2 week groups of experimental animals could not be analyzed. Among the 58 axons examined in the 4 week groups of animals, there were no overlapping hranches. Labeled RGC axons and their branches were drawn by camera lucida at a magnification of $100 \times$ (oil immersion). Axon and branch lengths were measured with an Image-I analysis system (Universal Imaging, West Chester, PA). Although some transected axons may have degenerated back in the retina from the site of $O N$ transection and then regrown toward the ON head, the only measurable indication of new axonal growth was that of the axons that turned at the ON head. The length of such growth was determined by measuring the distance from the point that the axon turned at the $\mathrm{ON}$ head to its termination in the retina.

Statistical methods. Quantitative results were analyzed with the SigmaStat program (Jandel, Corte Madera, CA). Data that failed tests of normality and equal variance were analyzed by the Kruskal-Wallis one-way ANOVA on ranks followed by Dunn's pairwise comparisons (Glantz, 1992).

\section{RESULTS}

In the 67 retinas examined, the axons of 652 individual $\mathrm{RGCs}$ were delineated by the Neurobiotin-peroxidase reaction product. These axons were analyzed for the location of their endings (over the retina outside the ON head or over the ON head), the presence of growth cones, the number and length of branches, and the appearance of aberrant growth. Substantial proportions (34$59 \%$ ) of the labeled axons in both the untreated (Table 1) and NT-treated (Table 2) retinas ended outside the ON head or at its edge (see Fig. 1). Many of these axons exhibited growth cones (Tables 1,2), suggesting that they had retracted into the retina and were attempting to regrow. The perikarya and dendrites of the labeled neurons were not analyzed in detail, but their size and appearance indicated that most were probably $\alpha$-RGCs.

In both the treated and the untreated retinas, axonal regrowth was revealed by the formation of new branches arising from axonal stumps and by aberrant axonal growth within the retina.

Table 2. Effect of NTs on RGC axon branches 2 weeks after ON transection

\begin{tabular}{|c|c|c|c|c|c|}
\hline & Cut only & $+\mathrm{BDNF}$ & $+\mathrm{NT}-4 / 5$ & $+\mathrm{NT}-4 / 5 \mathrm{p}^{a}$ & $+\mathrm{NT}-3$ \\
\hline Retinas $(n)$ & 11 & 17 & 2 & 3 & 13 \\
\hline Labeled axons $(n)$ & 92 & 195 & 27 & 17 & 139 \\
\hline Retracted $^{b}$ & $37(40 \%)^{d}$ & $115(59 \%)^{d}$ & $12(44 \%)$ & $7(11 \%)$ & $77(55 \%)$ \\
\hline With growth cones ${ }^{c}$ & $95 \%$ & $63 \%$ & $25 \%$ & $14 \%$ & $58 \%$ \\
\hline Axons with branches & $38(41 \%)$ & $77(39 \%)$ & $7(26 \%)$ & $8(47 \%)$ & $47(35 \%)$ \\
\hline Branches/axon & 6.8 & 6.2 & 8.9 & 9.9 & 7.8 \\
\hline Range & $1-42$ & $1-42$ & $1-44$ & $3-20$ & $1-29$ \\
\hline \multicolumn{6}{|l|}{ Branch length } \\
\hline Median $(\mu \mathrm{m})$ & 9.0 & $71.7^{*}$ & 5.2 & $72.1^{*}$ & 8.6 \\
\hline Range $(\mu \mathrm{m})$ & $1.7-1860.4$ & $2.1-1352.1$ & $1.4-60.6$ & $1.8-640.6$ & $1.4-1030.2$ \\
\hline$<5 \mu \mathrm{m}(\%)$ & $26 \%$ & $10 \%$ & $48 \%$ & $19 \%$ & $23 \%$ \\
\hline$>50 \mu \mathrm{m}(\%)$ & $21 \%$ & $5.5 \% * *$ & $2 \%$ & $51 \%$ & $20 \%$ \\
\hline
\end{tabular}

aContinuous administration by osmotic mini-pump.

${ }^{h}$ Axons that end outside the ON head or at its edge.

Proportion of axons outside the ON head that had growth cones.

"The ending of two axons could not be identified.

*Significantly greater than cut only. $p<0.001$, Kruskal-Wallis one-way ANOVA on ranks; $p<0.05$, Dunn's pairwise comparisons.

${ }^{*}$ Significantly greater than cut only. $p<0.05$, Student's $t$ test. 


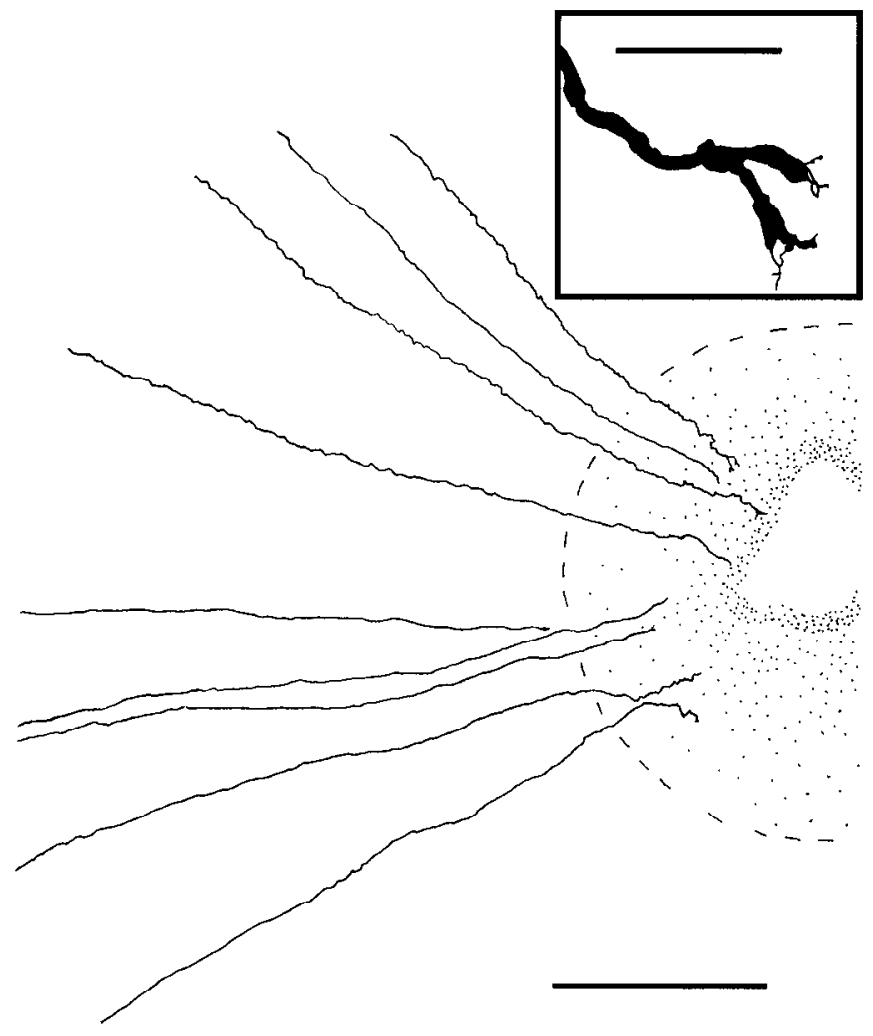

Figure 1. Camera lucida drawing of several Neurobiotin-filled RGC axons near the $\mathrm{ON}$ head in a retina $4-6 \mathrm{hr}$ after removal from the animal. The edge of the ON head is indicated by the broken lines. The axon at the top has two short terminal branches; the fifth axon from the top does not reach the $O N$ head, because of either retrograde degeneration or incomplete filling. Scale bar, $200 \mu \mathrm{m}$. Inset, The branched axon, which was severed at the onset of the ex vivo labeling 4-6 hr before fixation, ends as two growth cones. Axons that showed such growth cones over the ON head presumably terminated on the surface of the $\mathrm{ON}$ head and did not project into the ON stump. Scale bar, $20 \mu \mathrm{m}$.

\section{Axon branching}

In the retinas that did not receive NT injections at the time of ON transection, $21-41 \%$ of axons had branches that ranged in length from less than $10 \mu \mathrm{m}$ to nearly $2 \mathrm{~mm}$ (Fig. 2, Table 1). Most of these axon branches were observed within $200 \mu \mathrm{m}$ of the ON head (Fig. 3) and, based on the depth of focus in the flat-mounted retinas, they appeared to be confined to the nerve fiber layer. Both simple and complex patterns of axon branching were observed (Fig. 3). Axonal branching, as well as the appearance of growth cones (Fig. 1), was observed soon after axotomy; even when the ONs were transected only at the time of eye removal for intraneuronal injection, $31 \%$ of the labeled axons had short branches at the end of the 4-6 hr incubation (Table 1).

The incidence of axons with branches was similar (21-41\%) at the times examined: $4-6 \mathrm{hr}$ to 4 weeks. The ratio of branches/ axon among branching axons varied from 6.8 at 2 weeks to 20.8 at 4 weeks (Table 1), but the differences were not statistically significant. The incidence of axonal branching and the ratios of branches/axon were similar for axons in the NT-treated and untreated groups (Tables 1, 2).

\section{Branch lengths}

Examined 4-6 hr after axotomy, 87\% of the axon branches measured $<5 \mu \mathrm{m}$ (Table 1), lengths comparable to the "spikes" described in developing RGCs of amphibians (Cohen-Cory and
Fraser, 1995). The proportion of these short branches decreased to $26 \%$ by 2 weeks. The in vitro technique used to label RGC axons did not allow us to determine whether such spikes were an early response to axon injury or an intrinsic feature of the axons. However, the incidence of these short branches was not significantly affected by the application of NTs (Table 2).

A single injection of BDNF greatly increased RGC axon branch growth at 2 weeks (Fig. 4). Indeed, their median length grew eightfold from $9.0 \mu \mathrm{m}$ in the untreated retinas to $71.1 \mu \mathrm{m}$ in the BDNF-treated retinas, and the proportion of branches that were longer than $50 \mu \mathrm{m}$ increased significantly from 21 to $55 \%$ (Table 2, Fig. 5). This effect was specific for branch length and was not accompanied by an increase in the proportion of axons that had branches or in the number of branches formed by individual RGCs (Table 2). In the NT-3-trcatcd retinas, the number and lengths of branches did not differ from those of the untreated retinas (Fig. $3 C$, Table 2). Thus, the specific effect of BDNF was clearly to enhance the length of axonal branches. By 4 weeks after ON transection in both the NT-treated and the untreated retinas, median branch lengths were under $10 \mu \mathrm{m}$ and the proportion of branches longer than $50 \mu \mathrm{m}$ decreased to $<10 \%$ (Fig. $4 D-F$ ).

\section{Effect of continuous administration of NT-4/5}

To explore the possibility that a more prolonged availability of NT might affect the growth of axotomized intraretinal RGC axons, we compared the RGC axons after single injections or continuous infusion with an osmotic minipump of NT-4/5. This N' $\mathrm{I}^{\prime}$ is related to BDNF (Hallböök et al., 1991), binds to the TrkB receptor expressed by most rat RGCs (Jelsma et al., 1994), and is known to enhance the survival of injured RGCs. For technical reasons probably related to the tendency of the molecule to adhere to the constituents of these pumps, we were not able to administer BDNF in a prolonged manner. With continuous infusion of NT$4 / 5$ in three retinas, however, the median length of the RGC axon branches was $72.1 \mu \mathrm{m}$ ( $n=79$ branches), significantly greater than the median branch length of $5.2 \mu \mathrm{m}(n=62)$ observed in two retinas treated with a single injection of NT-4/5 at the time of ON transection.

\section{Growth away from the ON head}

In both the NT-treated and the untreated retinas, there were axons that turned at the $\mathrm{ON}$ head and grew toward the periphery of the retina (Fig. $3 A$ ). Such turning axons were seen as early as 3 $\mathrm{d}$ after $\mathrm{ON}$ transection; by 2 weeks, $\sim 10 \%$ of the axons studied exhibited this turning course and extended for distances that ranged from 28.5 to $1457.4 \mu \mathrm{m}$. Based on the distances that the turning axons elongated toward the periphery of the retina, which was the only reliable measurement of axon shaft growth available in this study, we found no evidence that any of the NTs increased the growth of the main axonal shaft of the injured RGCs.

\section{DISCUSSION}

Retinal ganglion cell axons cut in the ON or the eye can spontaneously regrow for short distances within the retina (Tello; Leoz and Arevate, cited by Ramón y Cajal, 1928); (Goldberg and Frank, 1980; McConnell and Berry, 1982). We previously showed that intravitreal injections of BDNF enhanced RGC survival and caused an increase in the density of axons in the vicinity of the ON head (Mansour-Robaey et al., 1994). It was not known, however, whether the greater number of RGCs was responsible for such an apparent increase in axonal profiles. The present studies establish that the administration of BDNF or NT-4/5, but not of NT-3, 


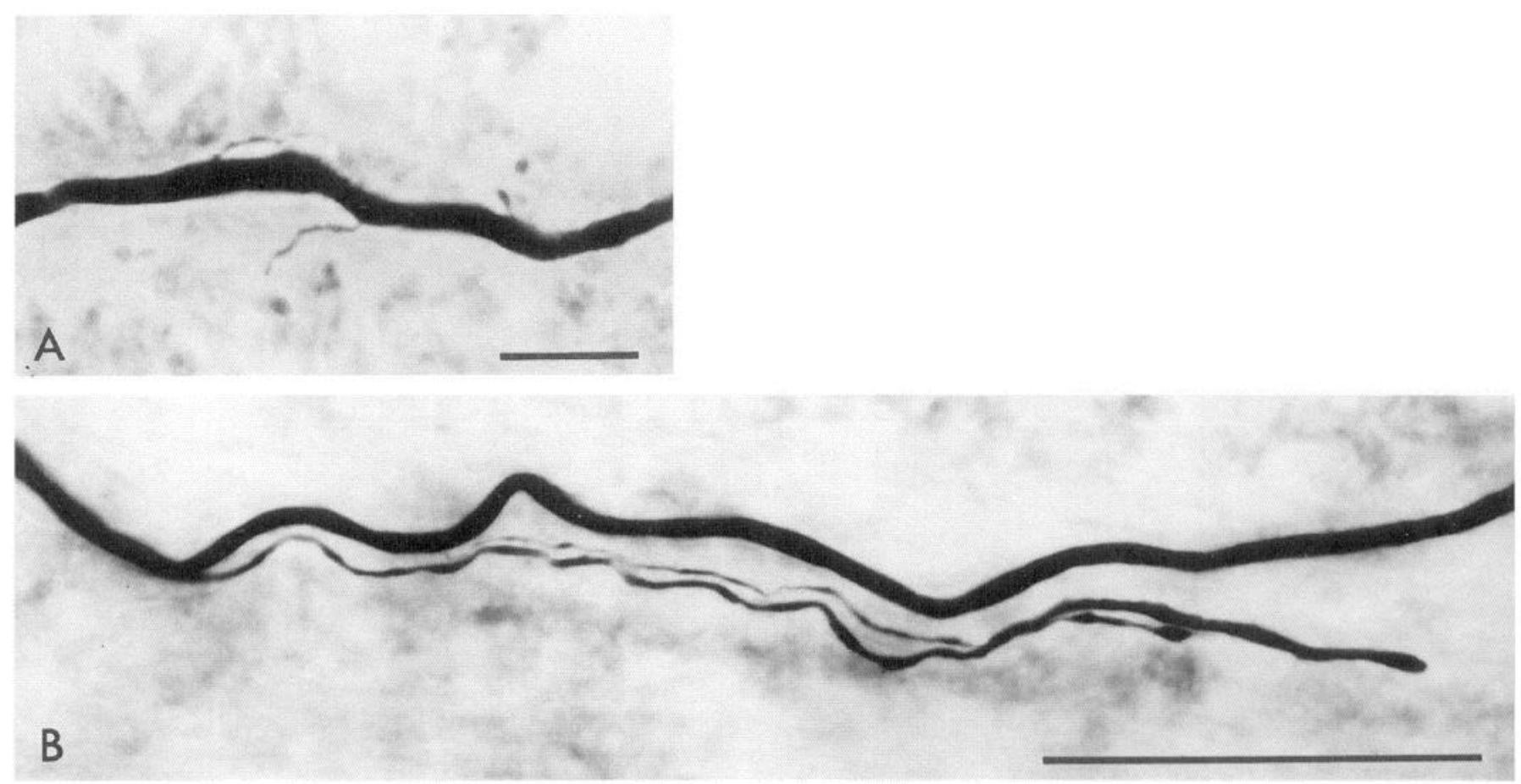

Figure 2. Photographs of two labeled RGC axons near the ON head. The shaft of each axon was traced to the RGC perikaryon to ensure that single, individual axons were being assessed. $A$, Two weeks after ON transection without NT administration, this axon has several small branches that are $<12$ $\mu \mathrm{m}$ in length. Scale bar, $10 \mu \mathrm{m}$. B, An axon from a retina that was treated with BDNF has two long branches that grow toward the ON head that are 94 and $153 \mu \mathrm{m}$ in length. Scale bar, $50 \mu \mathrm{m}$.

specifically promotes axonal branch growth within the retina. Thus, both increased survival and growth appear to have contributed to the meshwork of axonal profiles observed in retinas after BDNF administration (Mansour-Robaey et al., 1994).

The mechanisms whereby the NTs influence neuronal survival and regrowth may be independent of each other, as suggested by the in vitro evidence that neuronal viability and neurite extension are mediated by different domains of their preferred receptors (Garner and Large, 1994; Peng et al., 1995) and involve the activation of distinct cellular pathways (Rabin et al., 1993; Stevens et al., 1994; Peng et al., 1995; Jackson et al., 1996).

\section{BDNF or NT-4/5 increases RGC axon branch lengths}

Previous in vitro studies demonstrated that BDNF is capable of promoting neurite outgrowth (Lindsay, 1988; Cohen et al., 1994; Ahmed et al., 1995) or branching (Patel and McNamara, 1995). Recent in vivo investigations carried out in the developing visual system of Xenopus tadpoles (Cohen-Cory and Fraser, 1995) also indicate that branch length is stimulated by the administration of BDNF into the target regions of visual projections. Our documentation that BDNF and NT-4/5 can dramatically enhance the growth of axonal branches from axotomized RGCs in the mature rat eye suggests that the effects of NTs on axonal growth are similar during the development and regeneration of a given neuronal class. In both of these circumstances, BDNF appears to be essential for the extension of RGC axonal branches but had no apparent effect on the formation of new branches. Furthermore, in both development and regeneration, the growth of branches appears to depend on the supply of BDNF. Indeed, the administration of BDNF antibodies into the tectum of tadpoles abolished branching (Cohen-Cory and Fraser, 1995), whereas in our experiments branch lengths were increased 2 weeks after a single intravitreal injection of BDNF but diminished to control levels by 4 weeks.

The long axon branches observed at 2 weeks in the BDNFtreated retinas were not seen at 4 weeks. Although the death of the axotomized RGCs undoubtedly contributed to the decreased numbers of these branches, there also must have been a loss of long branches from the few neurons that survived at this time without additional BDNF (Mansour-Robaey et al., 1994). The loss of these branches in the absence of added BDNF provides additional support for the idea that BDNF is essential for axon branch growth.

In both the NT-treated and the untreated groups of retinas, $\sim 40 \%$ of the labeled RGC axons branched and regrew aberrantly in the vicinity of the $\mathrm{ON}$ head, the anatomical junction of the retina and the ON. Such a limited incidence of branching was also suggested by the observation that when BDNF was introduced into the tectum of the developing Xenopus, the branching of RGCs only increased in approximately one-half of the axons (Cohen-Cory and Fraser, 1995). Possible causes of this restricted neuronal responsiveness to BDNF include a limited expression of TrkB during development (Cohen-Cory and Fraser, 1994) or an impaired growth capacity of certain RGCs (Chen et al., 1995). The lack of regenerative branching in some RGCs may also be a sign of neuronal failure and impending death because so many of the axotomized RGCs are lost during the first 2 weeks after injury (Berkelaar et al., 1994).

\section{Effects of NT-3}

Although there was a trend toward greater numbers of small branches 2 weeks after NT-3 administration (Fig. $4 C$ ), the difference was not statistically significant. In contrast to what is observed in the retina, NT-3 administration does lead to increased 

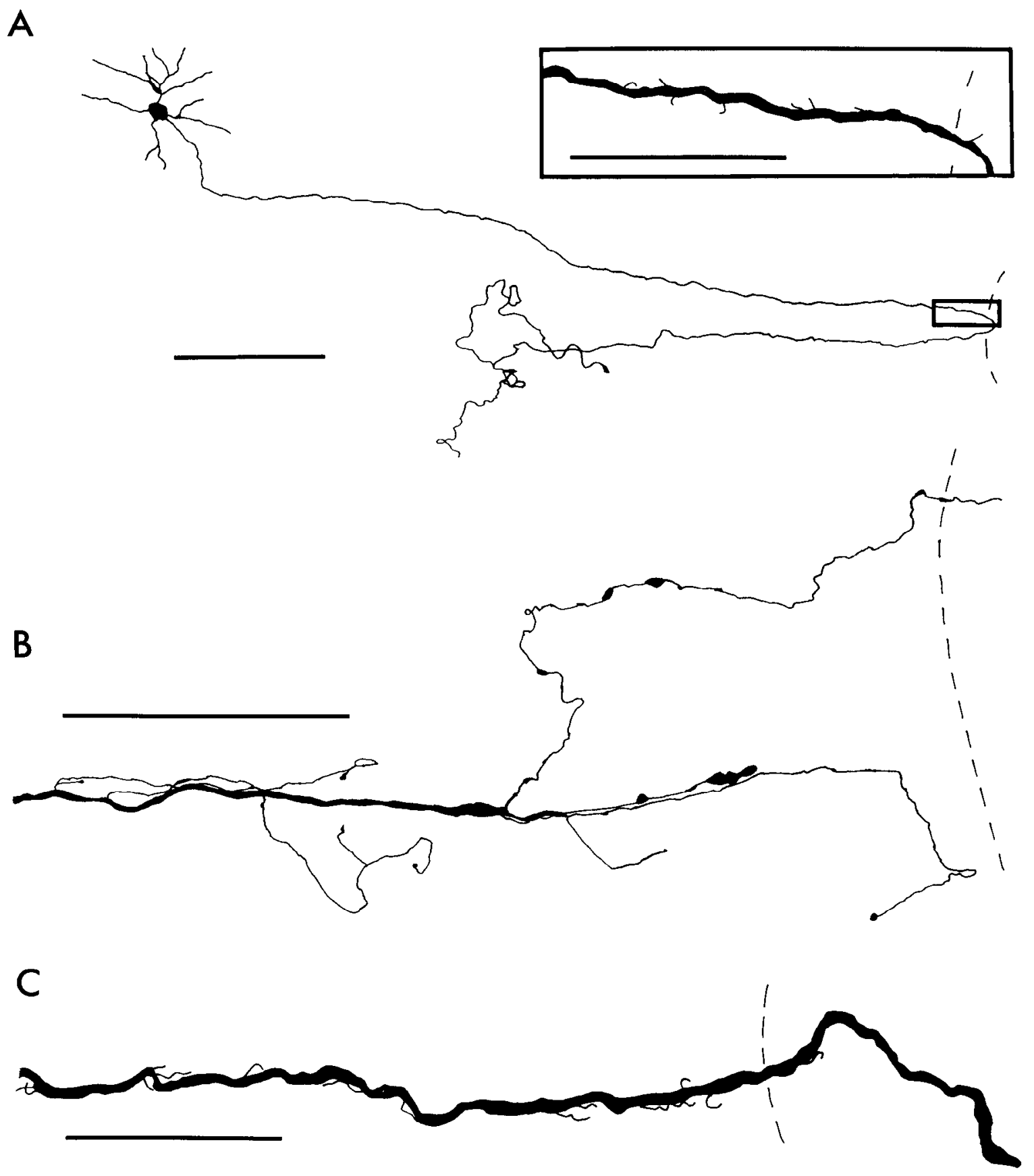

Figure 3. Camera lucida drawings of Neurubiotin-labeled RGC axuns in fil-mounled retinas 2 weeks after ON transection alone $(A)$ or with the intravitreal administration of BDNF $(B)$ or NT-3 $(C)$ at the time of ON transection. The broken lines indicate the edge of the ON head. $A$, An axon in an untreated retina turns at the edge of the ON head, grows toward the periphery of the retina for $824 \mu \mathrm{m}$, and then forms a branch that is $445 \mu \mathrm{m}$ in length. The main axon then turns toward the $O N$ head and ends as a growth cone. Scale bar, $200 \mu \mathrm{m}$. Inset, Drawn at higher magnification, the axon shown in $A$ also has numerous small branches near the $\mathrm{ON}$ head. Scale bar, $50 \mu \mathrm{m}$. B, An axon in a retina treated with $5 \mu \mathrm{g}$ of BDNF at the time of ON transection has eight branches that range in length from 11 to $363 \mu \mathrm{m}$. Scale bar, $100 \mu \mathrm{m}$. $C$, An RGC axon in a retina treated with $5 \mu \mathrm{g}$ of NT-3 ends over the ON head and has many short branches. Scale bar, $50 \mu \mathrm{m}$.

numbers of axonal "sprouts," presumably branches, after spinal cord lesions in adult rats (Schnell et al., 1994). Such differences in the growth factor responsiveness of nerve cells in these two regions of the mature rat CNS may reflect selective actions mediated by specific NT receptors expressed by the various classes of neurons involved.

Although we did not demonstrate an effect of NT-3 on branch formation by the overall population of RGCs, it is possible that this NT only affected a subset of these neurons that express $t r k \mathrm{C}$, its preferred receptor. In intact rat retinas, only $30 \%$ of the RGC population expresses this receptor, and its mRNA levels tend to fall after RGC axotomy (Kittlerova et al., 1995). In the present experiments, it was not possible to determine whether NT-3 increases survival and growth only in the subset of these neurons that express TrkC.

The possibility that NT-3 may have an effect on RGC growth that 


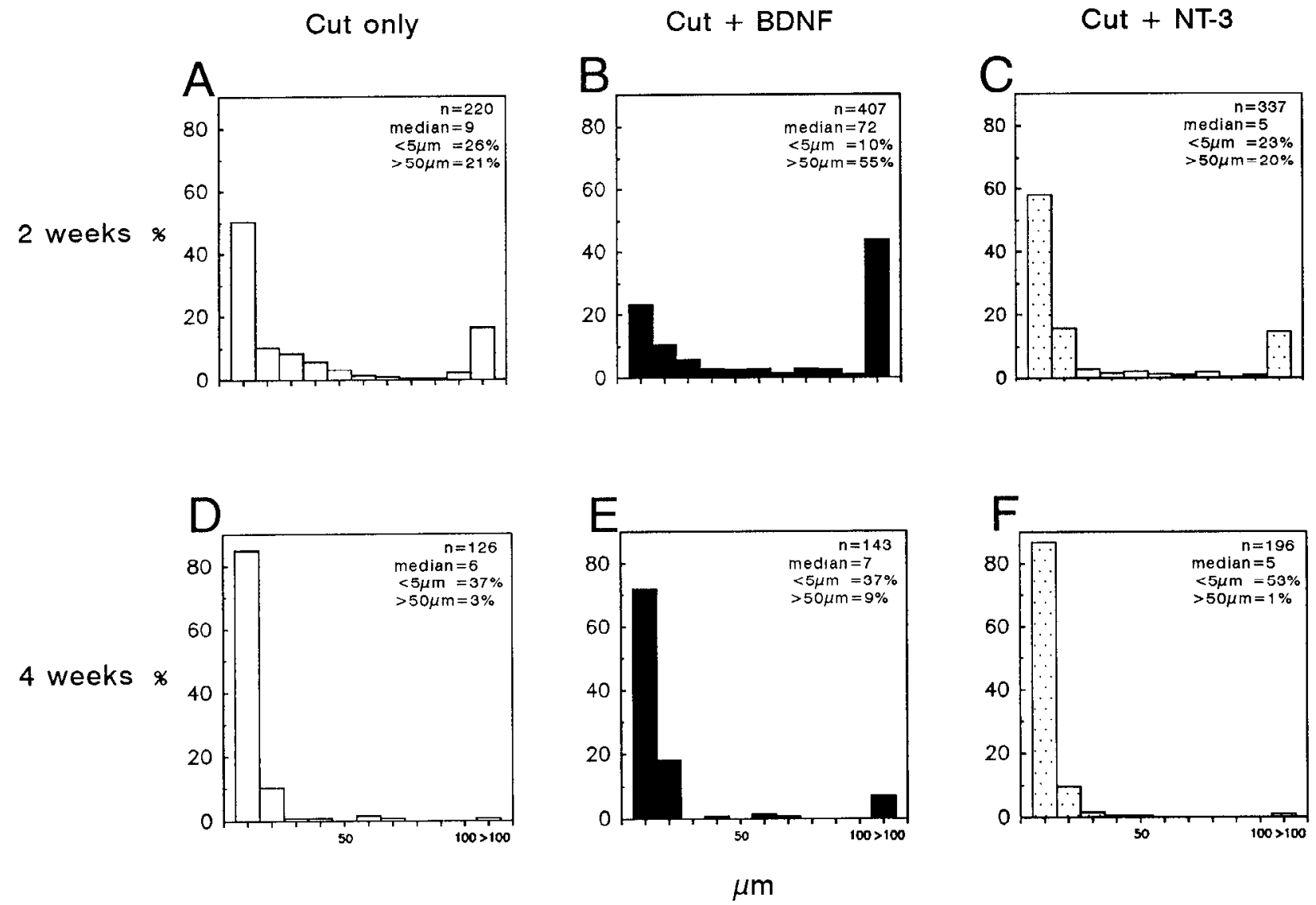

Figure 4. Histograms (binwidths, $10 \mu \mathrm{m})$ showing the distribution of RGC axon branches 2 weeks $(A-C)$ or 4 weeks $(D-F)$ after ON transection without added NT $(A, D)$, and after a single intravitreal injection of BDNF $(B, E)$ or NT-3 $(C, F)$. At 2 weeks, there were more long axon branches in the BDNF-treatcd retinas $(B)$ than in the untreated $(A)$ or NT-3-treated $(C)$ retinas. By 4 weeks, most branch lengths were $<10 \mu \mathrm{m}$ in all three groups $(D-F)$.

cscaped our detection is suggested further by the finding that NT-3 causes an increase in the number of short, spike-like branches in the developing retino-tectal pathway in tadpoles (Cory-Cohen and Fraser, 1995). Moreover, in adult rats GAP-43 is markedly enhanced in nearly one-half of the axotomized RGCs 2 weeks after injury and NT-3 administration (Kittlerova et al., 1994). The in vitro demonstration that GAP-43 expression correlates well with the branching of sensory neurons responsive lo NGF or IGF-1 (Aigner and Caroni, 1995 ) and that transgenic mice overexpressing GAP-43 show spontaneous nerve sprouting in response to injury (Aigner et al., 1995) suggests that the patterns of GAP-43 expression we have observed in
RGCs treated with NT-3 are indices of some form of growth stimulation by this NT.

\section{Failure of regenerating RGC axons to grow back into the ON head}

In both the untreated and the NT-treated retinas, nearly one-half of the labeled RGC axons that were cut behind the eye degenerated back toward their cell bodies in the retina for $\sim 0.5 \mathrm{~mm}$, the length of the ON stumps. This axonal degeneration positioned most growth cones within the retina in the vicinity of the ON head. Thus, the regrowth of $\mathrm{RGC}$ branches into the $\mathrm{ON}$ would require their orderly

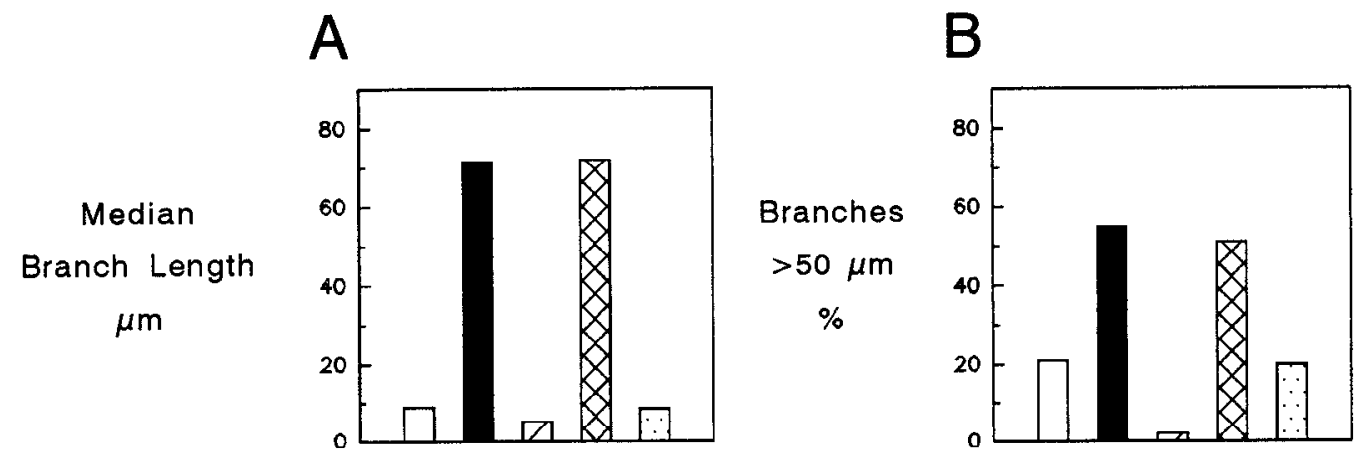

Figure 5. At 2 weeks, median branch lengths $(A)$ and the proportions of branches $>50 \mu \mathrm{m}$ in length were significantly greater in the retinas treated with a single injection of BDNF (black bars) or a continuous infusion of NT-4/5 (cross-hatched bars) than in the untreated retinas (open bars) or the retinas that received single injections of NT-4/5 (hatched bars) or NT-3 (stippled bars). 
extension toward the $\mathrm{ON}$ head and their penetration of this anatomical structure. In rodents, the ON head does not contain oligodendrocytes (Anderson and Quigley, 1992) that express inhibitors of axon growth (Schwab et al., 1993; McKerracher et al., 1994; Mukhopadhyay et al., 1994). Our demonstration that many of the RGC axons that retracted into the retina did not extend across or into the ON head but were diverted at its edges suggests that molecules unrelated to myelin may impair their growth. Possible candidates are chondroitin sulfate proteoglycan (Brittis et al., 1992; Cohen et al., 1995), tenascin (Bartsch et al., 1994), and collapsin (Luo et al., 1995). Because it has been suggested that certain membrane-bound inhibitors can enhance RGC arborization in the superior colliculus (Roskies and O'Leary, 1994), it is conceivable that putative molecules in the ON head also may have influenced the branching of the RGC axons in the retina.

The demonstration that NTs do not prevent the early dying back of injured RGC axons into the eye where they are blocked from reentering the $\mathrm{ON}$ could explain why an enhancement of RGC survival and growth was not paralleled by a greater regeneration into PN grafts attached to the ON (Mansour-Robaey et al., 1994). Although the capacity to sustain a lengthy regrowth has not been proven for all adult mammalian RGCs (Chen et al., 1995), the source of graft innervation may be restricted to axons whose growth cones remain within the ON stump, in the proximity of the end of the PN graft.

\section{Possible modulation of regenerated arbors by NTs}

$\mathrm{RGC}$ axons regenerating along peripheral nerve grafts can be guided to their targets in the SC where they form persistent and functional synapses (Vidal-Sanz et al., 1987; Carter et al., 1989; Kierstead et al., 1989; Sauvé et al., 1995). Individual regenerated axons form approximately normal numbers of terminal boutons, but their arborizations are about one order of magnitude smaller than normal (Carter, 1991; Carter et al., 1991). This failure of the terminal axon branches to extend is associated with an increased density of synapses in the partially innervated superior colliculi and may explain some of the electrophysiological characteristics of the focally concentrated RGC inputs found in the SC of animals with nerve grafts linking the eye and the dorsal midbrain (Sauvé et al., 1995).

The recent demonstration that BDNF increased branch length in the developing arbors formed by RGC axons entering the tectum of tadpoles (Cohen-Cory and Fraser, 1995) and the effects of $\mathrm{BDNF}$ and $\mathrm{NT}-4 / 5$ on regenerating $\mathrm{RGCs}$ in the adult rat retina documented in the present study strongly suggest that NTs contribute to the establishment of normal branching patterns not only in dendrites (McAllister et al., 1995) but also in axons. Furthermore, the effects of BDNF on the length of the RGC branches shown here (median $71.7 \mu \mathrm{m}$, maximum $1352 \mu \mathrm{m}$ ) would be sufficient to expand toward normal the small arbors observed when RGCs regenerate into the SC (Carter et al., 1991; Sauvé et al., 1995). Thus, a better understanding of the effects of growth factors on axons may help develop strategies to reshape the terminal fields that arise from the regeneration of these and other CNS pathways. The observation that the intracortical infusion of BDNF in kittens leads to an inhibition of the normal segregation of ocular dominance columns (Cabelli et al., 1995) underscores the need for a cautious approach to the use of these powerful molecules during development and regeneration.

\section{REFERENCES}

Ahmed S, Reynolds BA, Weiss S (1995) BDNF enhances the differentiation but not the survival of CNS stem cell-derived neuronal precursors. J Neurosci 15:5765-5778.

Aigner L, Caroni P (1995) Absence of persistent spreading, branching, and adhesion in GAP-43-depleted growth cones. J Cell Biol 128:647-660.

Aigner L, Arber S, Kapthammer JP, Laux T, Schneider C, Botteri F, Brenner H-R, Caroni P (1995) Overexpression of the neural growthassociated protein GAP-43 induces nerve sprouting in the adult nervous system of transgenic mice. Cell 83:269-278.

Anderson DR, Quigley HA (1992) The optic nerve. In: Adler's physiology of the eye (Hart Jr WM, ed), pp 616-640. St. Louis: Mosby Year Book.

Bartsch U, Faissner A, Trotter J, Doerries U, Bartsch S, Mohajeri H, Schachner M (1994) Tenascin demarcates the boundary between the myelinated and nonmyelinated part of retinal ganglion cell axons in the developing and adult mouse. J Neurosci 14:4756-4768.

Berkelaar M, Clarke DB, Wang Y-C, Bray GM, Aguayo AJ (1994) Axotomy results in delayed death and apoptusis of retinal ganglion cells in adult rats. J Neurosci 14:4368-4374.

Brittis PA, Canning DR, Silver J (1992) Molecular inhibition during retinal development and optic nerve regeneration. In: Systems of ophthalmology (Albert D, ed), pp 543-553. Boston: Harvard UP.

Cabelli RJ, Hohn A, Shatz CJ (1995) Inhibition of ocular dominance column formation by infusion of NT-4/5 or BDNF. Science 267:1662-1666.

Carter DA (1991) Differentiation of regenerated retinal ganglion cell connections in the superior colliculus of adult hamsters. PhD thesis, McGill University.

Carter DA, Bray GM, Aguayo AJ (1989) Regenerated retinal ganglion cell axons can form well-differentiated retinal ganglion cell axons in the superior colliculus of adult hamsters. J Neurosci 9:4042-4050.

Carter DA, Bray GM, Aguayo AJ (1991) Patterns of the arborizations made by retinal ganglion cell axons regenerating into the superior colliculus of adult hamsters. Soc Neurosci Abstr 17:568.

Carter DA, Bray GM, Aguayo AJ (1994) Long-term growth and remodelling of regenerated retino-collicular connections in adult hamsters. $\mathbf{J}$ Neurosci 14:590-598.

Chen DF, Jhaveri S, Schneider GE (1995) Intrinsic changes in developing retinal neurons result in regenerative failure of their axons. Proc Natl Acad Sci USA 92:7287-7291.

Cohen A, Bray GM, Aguayo AJ (1994) Neurotrophin-4/5 (NT-4/5) increases adult rat retinal ganglion cell survival and neurite outgrowth in vitro. J Neurobiol 25:953-959.

Cohen A, Bray GM, Aguayo AJ (1995) Adult rat retinal sections are not permissive for neurite growth and cell adhesion in vitro. Soc Neurosci Abstr 21:292.

Cohen-Cory S, Fraser SE (1994) BDNF in the development of the visual system of Xenopus. Neuron 12:747-761.

Cohen-Cory S, Fraser SE (1995) Effects of brain-derived neurotrophic factor on optic axon branching and remodelling in vivo. Nature 378:192-196.

Garner AS, Large TH (1994) Isoforms of the avian TrkC receptor: a novel kinase insertion dissociates transformation and process outgrowth from survival. Neuron 13:457-472.

Glantz SA (1992) Primer of bio-statistics. New York: McGraw-Hill.

Goldberg S, Frank B (1980) Will central nervous systems in the adult mammal regenerate after bypassing a lesion? A study in the mouse and chick visual systems. Exp Neurol 70:675-689.

Hallböök F, Ibáñez CF, Persson H (1991) Evolutionary studies of the nerve growth factor family reveal a novel member abundantly expressed in Xenopus ovary. Neuron 6:845-858.

Jackson TR, Blader IJ, Hammonds-Odie LP, Burga CR, Cooke F, Hawkins PT, Wolf AG, Heldman KA, Theibert AB (1996) Initiation and maintenance of NGF-stimulated neuritc outgrowth requires activation of a phosphoinositide 3-kinase. J Cell Sci 109:289-300.

Jelsma TN, Hyman Friedman H, Berkelaar MJ, Bray GM, Aguayo AJ (1993) Different forms of the neurotrophin receptor trkB mRNA predominate in rat retina and optic nerve. J Neurobiol 24:23-36.

Keirstead SA, Rasminsky M, Fukuda Y, Carter DA, Aguayo AJ, VidalSanz M (1989) Electrophysiologic responses in hamster superior colliculus evoked by regenerating retinal axons. Science 246:255-258. 
Kita H, Armstrong WA (1991) A biotin-containing compound N-(2aminoethyl)biotinamide for intracellular labeling and neuronal tracing studies: comparison with biocytin. J Neurosci Methods 37:141-150.

Kittlerova P, Bray GM, Aguayo AJ (1995) TrkC expression in intact and injured adult rat retinas. Soc Neurosci Abstr 21:1550.

Kittlerova P, Playford DE, Bray GM, Aguayo AJ (1994) NT-3 cnhances growth and upregulates GAP43 in subset of retinal ganglion cells after axotomy. Soc Neurosci Abstr 20:1098.

Lindsay RM (1988) Nerve growth factors (NGF, BDNF) enhance axonal regeneration but are not required for survival of adult sensory neurons. J Neurosci 8:2394-2405.

Luo Y, Shepherd I, Li J, Renzi MJ, Chang S, Raper JA (1995) A family of molecules related to collapsin in the embryonic chick nervous system. Neuron 14:1131-1140.

Mansour-Robaey S, Clarke DB, Wang YC, Bray GM, Aguayo AJ (1994) Effects of ocular injury and administration of brain-derived neurotrophic factor on survival and regrowth of axotomized retinal ganglion cells. Proc Natl Acad Sci USA 91:1632-1636.

McConnell P, Berry M (1982) Regeneration of ganglion cell axons in the adult mouse retina. Brain Res 241:362-365.

McKerracher L, David S, Jackson DL, Kottis V, Dunn RJ, Braun PE (1994) Identification of myelin-associated glycoprotein as a major myelin-derived inhibitor of neurite outgrowth. Neuron 13:805-811.

Mukhopadhyay G, Doherty P, Walsh FS, Crocker PR, Filbin MT (1994) A novel role for myelin-associated glycoprotein as a major myelinderived inhibitor of neurite growth. Neuron 13:757-767.

Patel MN, McNamara JO (1995) Selective enhancement of axonal branching of cultured dentate gyrus neurons by neurotrophic factors. Neuroscience 69:763-770.
Peng X, Greene LA, Kaplan DR, Stephens RM (1995) Deletion of a conserved juxtamembrane sequence in Trk abolished NGF-promoted neuritogenesis. Neuron 15:395-406.

Rabin SJ, Cleghon V, Kaplan DR (1993) SNT, a differentiation-specific target of neurotrophic factor-induced tyrosine kinase activity in neurons and PC12 cells. Mol Cell Biol 13:2203-2213.

Ramón y Cajal S (1928) Traumatic degeneration and regeneration in the optic nerve and retina. In: Degeneration and regeneration of the nervous system (May RM, ed), pp 583-596. New York: Hafner.

Roskies AL, O'Leary DDM (1994) Control of topographic retinal axon branching by inhibitory membrane-bound molecules. Science 265:799-803.

Sauvé Y, Sawai H, Rasminsky M (1995) Functional synaptic connections made by regenerated retinal ganglion cell axons in the superior colliculus of adult hamsters. J Neurosci 15:665-675.

Schnell L, Schneider R, Kolbeck R, Barde Y-A, Schwab ME (1994) Neurotrophin-3 enhances sprouting of corticospinal tract during development and after adult spinal cord lesion. Nature 367:170-173.

Schwab ME, Kapfhammer JP, Bandtlow CE (1993) Inhibitors of neurite growth. Annu Rev Neurosci 16:565-595.

Stephens RM, Loeb DM, Copeland TD, Pawson T, Greene LA, Kaplan DR (1994) Trk receptors use redundant signal transduction pathways involving SHC and PLC-G1 to mediate NGF responses. Neuron 12:691-705.

Vidal-Sanz M, Bray GM, Villegas-Pérez MP, Thanos S, Aguayo AJ (1987) Axonal regeneration and synapse formation in the superior colliculus by retinal ganglion cells in the adult rat. $J$ Neurosci $7: 2894-2909$. 